\title{
Development of Staff Cultural Capacity in an Intensive Environmental Stewardship Program for Urban Youth
}

\author{
Rupanwita Gupta, PhD (corresponding author) \\ New Knowledge Organization Ltd. \\ 349 Fifth Ave, Suite 311, New York, New York 10016, United States \\ Tel: 1-347-766-3399 E-mail: rgupta@newknowledge.org \\ John Fraser, PhD AIA \\ New Knowledge Organization Ltd. \\ 349 Fifth Ave, Suite 311, New York, New York 10016, United States \\ Tel: 1-347-766-3399 E-mail: jfraser@newknowledge.org
}

Shelley J. Rank, MA

New Knowledge Organization Ltd.

349 Fifth Ave, Suite 311, New York, New York 10016, United States

Tel: 1-347-766-3399 E-mail: srank@newknowledge.org

Received: October 3, 2014 Accepted: October 21, 2014

doi:10.5296/emsd.v3i2.6401 URL: http://dx.doi.org/10.5296/emsd.v3i2.6401

\begin{abstract}
Cultural competence training for environmental educators has typically focused on formal professional development activities. The current research examined how educators can develop cultural competence through interaction with youth in environmental stewardship programs. An online survey was conducted with staff working closely with youth in The Nature Conservancy's Leaders in Environmental Action for the Future program, to study their learning experiences. Responses were available from 34 staff (completion rate $=51 \%$ ). Open-ended responses revealed they had learned about cultural differences in urban and youth
\end{abstract}


groups' engagement with the environment compared to that of adults in rural areas. In contrast, their understanding of different racial and ethnic groups was already high, and had not been impacted meaningfully. Quantitative items indicated that cultural competence about multiple conservation viewpoints $(\mathrm{M}=4.30, \mathrm{SD}=.33)$ was higher than that about racial and ethnic groups $(\mathrm{M}=4.07, \mathrm{SD}=.37), t(33)=4.30, p<.001$. Across questions staff reiterated that contact with interns had helped them develop greater appreciation for conservation work than before for its relevance to a wider segment of society. Rethinking conservation priorities was emotionally taxing for some staff and suggested that structured strategies for reflections on their cultural understandings are imperative for a diverse environmental workforce for the present and future.

Keywords: Cultural Competence, Conservation, Professional Development

\section{Introduction}

\subsection{Background}

With emerging focus on urban-based conservation education efforts (Krasny, Lundholm, Shava, Lee, \& Kobori, 2013), the environmental education (EE) field recognizes the need for culturally competent professionals who work with audiences from a range of backgrounds, experiences, and geographical locations. This trend is reflected in the North American Association for Environmental Education's (NAAEE) emphasis on culturally proficient efforts in the contemporary multicultural world of EE. Specifically, NAAEE's stance underscores how cultural competence will impact educators' work with their audiences, especially those with cultural backgrounds contrasting with theirs. These recent efforts, however, seem to focus on structured professional development for educators. In contrast, there is less attention on opportunities to foster cultural competence skills through their interaction with participants in environmental stewardship programs, such as those focused on conservation education. To meet the needs of a rapidly urbanizing world with unique environmental challenges, research needs to consider expansively the multiple arenas and settings for educators to develop cultural competence. The current research was conducted to study how an environmental stewardship program with collaborations between urban youth and program staff could help foster staff cultural competence. The study sought to understand how staff's interaction with youth promoted an expanded understanding of culture, beyond racial and ethnic boundaries, to include distinct perspectives on the environment and conservation work.

\subsection{Literature Review}

\subsubsection{Role of Culture in Environment-Focused Work}

The context of EE mirrors that of multicultural education (Nordström, 2008), where both fields offer opportunities to advance positive change in personal and societal-level outcomes. Nordström's proposition that EE manifests in multicultural ways is especially relevant in applied settings featuring multiple groups and environmental arenas. In fact, multicultural EE programs emphasize diversity, whether in relation to people's backgrounds, the program content, or the pedagogy and processes reflecting respect for different worldviews (Marouli, 2002). 
Agyeman (2002) has explicitly acknowledged the diverse perspectives on EE; however, his pressing call to reframe EE to encompass and embrace its cultural dimensions points to the lack of urgency across the field. He argues that the social and cultural ramifications of different voices in EE are intrinsically tied to power structures that exist in the field and need to be surfaced to avoid ethnocentrism and towards creating more meaningful EE practice (Agyeman, 2003).

The integration of the cultural influence in EE highlights that the work context of environmental educators and conservationists may be especially conducive to learn about different ways of approaching environmental-focused efforts. More recently, Tallis and Lubchenco (2014) posit that training conservationists to embrace diverse views should be part of their academic training and needs to be reinforced over time through professional development opportunities to highlight the range of perspectives to the work. Their appeal highlights the interplay of complex human experiences that underlie our multifaceted interactions with nature, including conservation actions. Conservation, considered the wise use of natural resources, such as water and land, emphasizes human dependence on nature (Ford, 1986), and further underscores the range of cultural experiences with nature, depending on their value-specific interaction. With this conceptualization, the current research considers conservation education one among numerous ideologies to teach about the human relationship with the environment.

Professionals involved in environmental-focused work, including conservation education, are known to hold a range of perspectives about their field, guided by multiple philosophies and methods of work. Given this multiplicity of perspectives, it is not surprising that communication difficulties may emerge in any interaction, especially around divergent values surrounding EE (Disinger, 1997). In fact, recent strides have highlighted that environmental educators' unique perception of EE's purpose may overshadow any shared goals through their work's larger aims (Fraser, Gupta, \& Krasny, 2014). For example, two educators each of whose primary focus is to foster environmental stewardship as a moral imperative or as a means to promote community empowerment may overlook their common goal to develop youth competencies. Disconnect in communication also prevents healthy, productive dialogue and access to funding to advance conservation goals (Tallis \& Lubchenco, 2014), thus hindering progress in the field.

The value of respecting myriad worldviews on the environment has been made explicit across decades. However, its translation to practice has been more challenging, since the necessary broadening of perspective beyond one's own requires skill, time, and concerted effort to develop (Kato, 2002). Viewing cultural competence around the environment as a necessary professional skill additionally implies this can be inculcated through relevant experiences.

The process in which a shift in thinking might occur has to recognize the complexity of human experience. Though acknowledgement of and respect for diverse viewpoints and beliefs surrounding conservation education has been encouraged to facilitate greater communication and networking to nurture a richer field (Schulze, 2005), inherent challenges are posed in its execution. For example, research has revealed the complex emotional underpinnings of 
conservationists' work (Fraser, Pantesco, Plemons, Gupta, \& Rank, 2013). This research surfaced that grappling with the daily realities of the world's environmental conditions is likely to lead to more heated emotions when a small disagreement is perceived as a threat to values, often escalating discord rather than mediation. As a consequence, what is precluded by such emotional reactions is a critical reflection on one's own views on conservation relative to that of others' to examine why perspectives are perceived to diverge. The study suggested that close examination of conservationists' competencies with emotional regulation and self-reflection are important measures to understand their ability to develop cultural competencies when working with others who do not share their views. To the extent that conservationists can appreciate and respect other 'ways of knowing' about the environment, they also are more likely to help the field achieve its goals.

Based on research on the various perspectives about the role of EE (Fraser et al, 2014), a professional development tool has been developed to facilitate educators' reflections on their personal beliefs about the field of EE (Fraser \& Gupta, 2012). In the form of a card-sorting activity, the professional development tool is designed to help environmental educators clarify their understanding of their work and to appreciate its relation to a wide spectrum of views of the field. The ultimate goal of such efforts to assess and examine educators' personal perspectives is to acknowledge and increase dialogue about different cultural approaches to EE.

What has emerged from these efforts is that culture is embedded in the multiple ways people conceptualize their conservation work (e.g, Kahn, 1999), with critical implications for their professional practice as well as the audiences with whom they work. An appreciation of different cultural approaches to conservation is expected to facilitate collaborations and partnerships within the field, as seen in capacity building training programs (Gupta, Fraser, \& Krasny, in preparation), and also develop the cultural competence skills of conservationists as they are increasingly called on to work with stakeholders who do not share their views. Conservationists' critical reflections, for example, may strengthen not only their awareness about diverse ways of practicing conservation, but may also increase their skills for working with groups with whom they are not familiar.

\subsubsection{Cultural Competence Research}

One of the arenas where cultural competence has been closely studied is in health-care settings where increased interactions between health-care providers and patients from diverse backgrounds and cultures have challenged traditional practices and authority (Doorenbos, Schim, Benkert, \& Borse, 2005). Doorenbos and colleagues' research led to the development of a cultural competence assessment tool that distinguishes knowledge, attitude, and behavioral outcomes in the context of experiences with diverse cultures. Their cultural competence research assessed i) diversity as exposure to people with a range of backgrounds; ii) cultural awareness as knowledge of the ways in which cultural groups negotiate group boundaries; iii) cultural sensitivity as an acknowledgement of others' viewpoints and respect for different ways of life; iv) cultural competence behaviors based on their own self-reports of their observations, awareness, and sensitivity to the norms and expectations of people from different cultures. 
In conservation education settings where different cultural groups may approach concepts of environment in different ways, it is possible to conceive an assessment of cultural competence based on this health model. The current study suggests that cultural competence measures, whether within the groups of staff or their interactions with community stakeholders are all places where these skills will come into play.

For purposes of this study, we approached the question of cultural competence by suggesting that audiences of conservation efforts, especially in urban settings, come from different cultural backgrounds with distinct perspectives on the meaning of conservation work, that differ starkly with the educators interacting with them. We note that our conceptualization of 'culture' is more expansive than racial and ethnic understandings (see Triandis, 1996). Rather, it is defined as the complexity of values, habits, behaviors, and customs shared by any group in society, making it relevant even in groups defined by their urbanity, for instance. At its core, the study is based on the premise that 'cultural background' is also related to experience in multicultural inner cities where income disparities and social conventions are radically different from those found in rural parts of the US.

\subsection{Research Questions}

The research sought to answer the following questions:

1. How do conservation program staff members working with urban youth develop cultural competence?

2. What are the unique ways staff members understand the cultural ramifications of environmental work?

3. What is the relationship between the staff's understanding of cultures of the environment and cultures based on race and ethnicity?

These questions were explored in the context of The Nature Conservancy's flagship youth program, the Leadership in Environmental Action for the Future or LEAF program.

\subsection{Research Context}

The Nature Conservancy (TNC) has developed a model for supporting youth development and diversifying the green jobs workforce through a summer youth program called Leaders in Environmental Action for the Future (LEAF). The model brings teens from urban high schools that are LEAF partners, into an intensive one-month program in July led by an experienced mentor in collaboration with TNC field staff in a range of outdoor, nature settings across the US. The program was developed in New York City over a 19-year period and has progressively expanded to other cities. In 2012, the program included youth from eight cities (New York City, NY, New Haven, CT, Plainfield, NJ, Atlanta, GA, Boston, MA, Chicago IL, Tacoma, WA and Los Angeles, CA).

New Knowledge Organization Ltd., a think tank based in New York City, has been working closely with LEAF since 2012, supporting the program through their research and evaluation expertise. Evaluation of LEAF has been undertaken via a mixed method, multi-phase, 
multi-level approach to comprehensively learn of its impacts. While the primary focus of the 2012 evaluation was on youth impacts, including their individual growth and development as cultural change agents, another effort focused on TNC staff impact, in particular, their development of cultural competence. The current study was designed to uncover the extent to which involvement with LEAF interns had exposed TNC staff to, expanded their thinking about, and increased their valuing of different cultural perspectives on conservation.

\section{Method}

NewKnowledge collaborated with TNC education staff to develop a cultural awareness and impacts survey to conduct with staff who had direct interaction with 2012 LEAF summer interns. The online survey was deployed in October 2012, three months following the end of the summer internships, and closed in the middle of November.

\subsection{Instrument}

Since the intent of the survey was to link staff experiences to specific youth outcomes tied to location, the responses were not considered anonymous but part of a monitoring program to improve LEAF. The survey included open-ended questions that helped identify staff to the researchers but was reported in aggregate and not shared in this report. The survey included quantitative items assessing staff's levels of cultural competence, their appreciation of youth-held perspectives on conservation, self-reports of interactions with the youth, how those interactions affected outcomes; and open-ended reflective questions about the extent to which staff can make these connections. Additional Likert scale questions pertaining to the cultural assessment of the staff's LEAF summer experience, as well as a few categorical questions about background of staff members (see Appendix A) were included.

\subsubsection{Cultural and Conservation Competence}

The main quantitative items included in the survey were based on the cultural competence measure developed by Doorenbos et al. (2005). A set of 20 items assessed staff competence and comfort when encountering people from different cultural backgrounds and holding perspectives on the 'environment' and 'nature' diverging from their own. A set of ten items each assessed cultural competence, conceptualized specifically as racial-ethnic cultural competence and conservation-related cultural competence.

The cultural competence items were developed based on the framework incorporating knowledge and attitudes developed by Doorenbos et al. (2005). Aspects of cultural competence that were measured include cultural diversity, cultural awareness, cultural sensitivity, and cultural competence behaviors. Items about respecting and valuing different beliefs and understandings of nature were based on recent research geared towards increasing conservationists' cultural capacity (Fraser et al., 2014; Fraser \& Gupta, 2012).

\subsubsection{Background Information}

Open-ended and multiple choice questions assessed the number of years staff had been involved with LEAF, their experience with youth, where staff grew up, and where they went to college. These background variables were included to assess the extent to which the type 


\section{Macrothink}

of location (such as, urban, suburban) where they grew up and where they went to college, and their experience working with youth, related to variation in racial-ethnic and conservation-related cultural competence.

\subsection{Participants}

Study participants were TNC staff located at each of the locations where the high school students interned. Figure 1 indicates the locations across the US where different groups of interns worked.

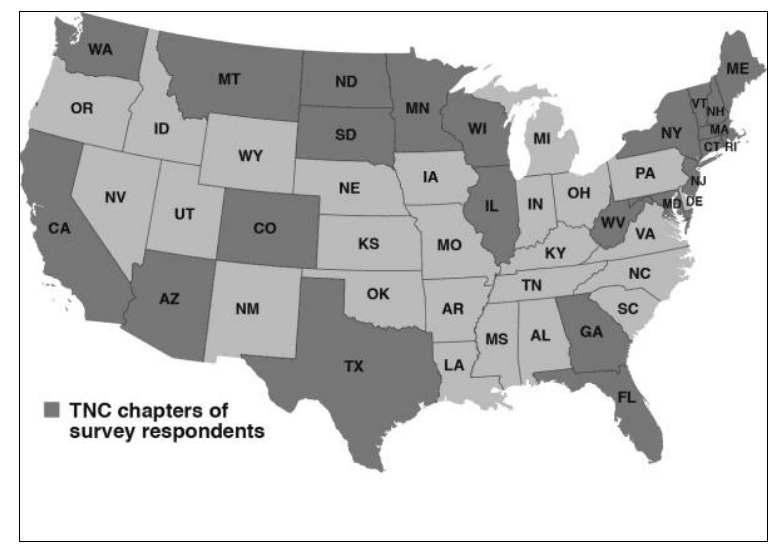

Figure 1. States where TNC staff was located and where the internships occurred.

TNC staff members were field biologists and ecologists, including but not limited to wildlife ecologists, wetland ecologists, and restoration ecologists. There were between one and three staff members at each location, with varying levels of interaction with the interns and their mentors.

\subsection{Analysis}

Frequencies of staff's responses to the multiple choice questions on the categorical variables were reported, as well as frequencies and means of Likert scale responses, ranging from 1 (Strongly Disagree) to 5 (Strongly Agree). Correlations between racial-ethnic and conservation-related cultural competence measures were calculated. Paired comparisons of differences between the two measures of cultural competence were calculated with T-tests.

\section{Results}

A total of 42 staff participants of the 2012 LEAF summer program responded to the cultural assessment online survey, indicating a response rate of $62 \%$. However, only 34 of these staff members completed the surveys, with a completion rate of $51 \%$. Staff respondents were from 20 different LEAF chapters, representing 22 states (See Figure 1).

\subsection{Staff Background}

Most of the 33 respondents to the question mentioned that they had not worked with youth before their involvement with $\operatorname{LEAF}(64 \%, \mathrm{n}=21)$. Even for those who had worked with urban youth before, the experience was listed as a rare occurrence [sometimes $(n=9)$ or rarely $(n=7)$ ]. 
Staff had been involved with LEAF for a range of years. Of the 34 respondents to this categorical question, the majority $(88 \%, \mathrm{n}=30)$ had previously worked with the LEAF program between one and four years. The single most frequently answered response for their participation was one year $(41 \%, \mathrm{n}=14)$.

Half the 34 respondents $(50 \%)$ reported spending the entire four-week internship period with the high school interns $(\mathrm{n}=17)$, while an additional six $(18 \%)$ reported working with the teens for at least two weeks. Four members (12\%) of the TNC field staff chose "Other" when asked how much time they had spent with the teen interns, of which three had contact with the interns for at least three weeks. In effect, $80 \%$ of staff respondents spent at least half the time of the internship interacting with these youth.

Nearly $38 \%$ of staff respondents reported attending college in an urban area $(n=13)$, while only two staff members reported growing up in an urban area. When asked about the racial and ethnic groups of people they tended to socialize most with, 59\% $(n=20)$ said they socialized principally with others of the same cultural background. The remaining respondents $(n=14)$ indicated they spent equal amounts of time socializing with people from the same and different culture as their own.

\subsection{Culture and Conservation}

Table 1 indicates how staff participation in LEAF influenced or exposed them to different cultural or conservation realities. Overall, the strongest agreement staff had was with the statement about being exposed to cultures other than their own, and about expanding their thinking on conservation.

Table 1. Attributions of how LEAF exposed staff to different cultures $(\mathrm{N}=34)$

\begin{tabular}{|l|l|l|}
\hline LEAF... & Mean & SD \\
\hline Exposed me to cultures other than my own. & 4.29 & .58 \\
\hline Helped me expand my thinking about conservation. & 3.74 & .83 \\
\hline Helped me value cultures other than my own. & 3.59 & .93 \\
\hline Helped me interact with people who approach conservation in other ways. & 3.53 & .79 \\
\hline
\end{tabular}

The explanations supporting the ratings in Table 1 shed further light on how they thought about culture and conservation, as presented next.

\subsubsection{The Value of Exposure to Other Cultures}

When asked how LEAF had exposed staff to cultures other than their own, the majority described exposure to diverse 'cultures' beyond racial and ethnic boundaries - that is, through engagement with teenagers from urban areas $(n=25)$, even though they may not have perceived it as another 'culture':

I was exposed to other [worldviews] about the environment and how people who live in inner cities see environmental problems. This is not necessarily another culture but it is another way of living and it helped me to understand another worldview

Another 14 staff acknowledged that many of these interns were from different countries, emphasizing cross-national awareness. 
Staff's responses also highlighted that they perceived differences in youth and adult cultures that were intertwined with the different cultures based on residential location. They defined cultural norms by the extent to which their residential location was urban, thus, considering urban or non-urban areas as prime drivers of culture rather than socio-demographic factors such as race that are typically referred to in political reporting. It is likely that this urban/rural distinction may have surfaced because conservation education work is as much tied to biogeography as to factors like race, as described in this response:

There is a huge difference in cultures from rural western areas and urban eastern areas. I enjoy learning about these differences. There are also cultural differences from being a teenager and [being] a professional conservationist. Things I take for granted are new and foreign to the students and bring up a lot of discussions. LEAF fosters the time between myself and students, giving us time to talk about these differences in how we view the world and better understand where people are coming from.

In describing how staff's participation with LEAF helped them value other cultures, about a third of the responding field staff said they already valued other cultures. Some suggested that the time they spent with the interns and mentors, sharing stories and personal histories, helped them better appreciate the differences between their cultural experiences and how these youth developed their values. This sharing experience was noted by many of the respondents.

Everyone has a story. To the extent we shared stories, we learned more. In looking back, I wish I had made more storytelling time.

These findings indicated that differences were perceived not just in the traditional racial or ethnic conceptualizations of culture but also in an unconventional manner, by focusing on urban and teen cultures to which field staff was exposed during the LEAF program.

\subsubsection{Conservation Views}

Nearly all the respondents affirmed that their interactions with interns had indeed helped them learn about approaches to conservation that were different than theirs. About half mentioned that several interns viewed conservation through an anthropocentric lens, such as in relation to social justice concerns, or by engaging in recycling and composting, or participating in active restoration. One respondent expanded on how interns' understanding of conservation focused primarily on urban natural resource maintenance:

[I was] not able to delve deeply into how the students approached conservation except that it appeared to be much more focused on natural history interpretation, city park[s,] trail work, and projects that were in areas that [they] were, because of their intense urban use, in constant need of maintenance, rather then restoring natural systems that would - with just a little help be repaired and function naturally.

Others described their experience with interns, as working with "an open- ended book," indicating substantial potential to learn from them. Several of these staff felt that interns had not established a particular view about conservation, perceiving them to be in an impressionable stage with the capacity to develop them further. Most of this group 
acknowledged interns' fluid views on conservation without attempting to influence them.

When asked to elaborate on the process in which LEAF helped staff broaden their thinking about conservation, many said they felt their experience interacting with and learning about urban teen life had expanded their understanding of approaches to conservation. These experiences encouraged many to think about conservation from an urbanite's point of view. Even as they broadened their ideas about conservation, some grappled with this new thinking, as it challenged their strongly held beliefs about priorities, a shift that they had not expected:

..Engaging with the LEAF program definitely helps me to see or at least appreciate the perspective of those that do live in the urban setting and the need to make conservation relevant to them by bringing our science expertise and conservation ethic into their surroundings.

A prevalent theme across the various responses was the staff's focus on strategies and approaches to teach conservation in ways that resonated with urban youth's perspectives. This was considered critical to engage youth audiences in conservation efforts in ways that resonated with how they conceptualized nature and cared for it:

We seem to be so focused on biodiversity, we forget sometimes about the people aspect of conservation. The interns pointed out that if we protect our lands, we can still see the stars at night. Their ability to see the stars above them really shaped their experience. I hadn't ever thought of it that way.

Despite the small sample size, the open-ended responses indicated that staff was very aware of the stark differences between their cultural models and those held by urban youth. These results suggested that the staff's socio-economic backgrounds might have influenced the lens through which they interpreted their interactions, emphasizing the value of exploring their cultural history in future assessments.

\subsection{Racial-Ethnic and Conservation-Related Cultural Competence}

As seen in Table 2, ten statements assessing staff's racial-ethnic cultural competence indicated modest internal consistency measured with Cronbach's alpha $(\alpha=0.64)$.

Table 2. Means for items depicting racial-ethnic cultural competence $(\mathrm{N}=34)$

\begin{tabular}{|c|c|c|}
\hline & Mean & SD \\
\hline Individuals may identify with more than one cultural group. & 4.56 & .56 \\
\hline I welcome feedback from co-workers about how I interact with people from other cultures. & 4.53 & .56 \\
\hline I welcome feedback from my interns about how I relate to people from other cultures. & 4.53 & .51 \\
\hline I enjoy working with people from other cultural backgrounds. & 4.50 & .62 \\
\hline Race is the most important factor in determining a person's culture. ${ }^{*}$ & 4.12 & .77 \\
\hline I learn from my interns about other cultural heritages. & 4.09 & .62 \\
\hline Aspects of cultural diversity need to be assessed for each individual, group, and organization. & 4.03 & .90 \\
\hline People with a common cultural background think and act alike.* & 3.97 & .90 \\
\hline I learn from my co-workers about other cultural heritages. & 3.71 & .76 \\
\hline I document the adaptations I make with my interns from other cultures. & 2.68 & .77 \\
\hline
\end{tabular}

* Reverse coded items 
Staff's ratings were mostly high on the 5 point Likert scale, and indicated they acknowledged that culture could be conceptualized broadly, so that people held more than one cultural identity. They also explicitly indicated that there was more to 'culture' than race. That their cultural learning through interactions with the interns was rated higher compared to that with their colleagues, reinforces the open-ended responses they provided. That they were less inclined to document how they had to be mindful of interactions with interns from other cultures, suggests they may not recognize its value and implication for their professional work.

When examining the relationships between the items, the correlations between these ten items did not indicate any significant relationships, and may be due to the small sample size. In general, the items assessing the actions they could take to increase cultural competence indicated stronger relationships than the items assessing awareness and sensitivity to cultural issues. The strongest relationships were demonstrated between the pair of items assessing learning about different cultures from interns and coworkers $(r=.90, p<.001)$, and the pair acknowledging that race is not the only distinguishing feature of one's culture and that people from the same culture think and act differently $(r=.53, p<.001)$. When the latter two items were excluded, as suggested by the computation of Cronbach's alpha, the internal consistency of the items increased to a more acceptable value of .71, and hence, these eight items were used to calculate the mean cultural competence. As a result the racial-ethnic cultural competence measure depicted beliefs appreciating and learning from different cultural groups, and acknowledging the multidimensional nature of culture.

An additional set of ten items asked about multiple cultural understandings about environmental issues as seen in Table 3. The high mean ratings for the most part indicated strong awareness of different perspectives on conservation and environment-related work. The strongest agreement was seen in items recognizing the multiplicity of views, appreciating the differences, and valuing their impact on the conservation field. The items that reflected how they might navigate different beliefs about conservation in their professional work (in terms of enjoying working with others with contrasting views, and adapting their views to the interns' cultural understandings) were rated somewhat lower; this suggested that putting their broadened cultural understandings into practice was challenging and might require strategies to bridge the gap between beliefs and action.

Table 3. Means for items depicting conservation-related cultural competences $(\mathrm{N}=34)$

\begin{tabular}{|c|c|c|}
\hline & Mean & $\mathrm{SD}$ \\
\hline I understand that others may think about the word "environment" differently than me. & 4.65 & .49 \\
\hline Different perspectives on conservation strengthen the field. & 4.65 & .54 \\
\hline I am aware that people think about conservation in different ways. & 4.62 & .49 \\
\hline I can appreciate ways of thinking about conservation other than mine. & 4.47 & .51 \\
\hline Knowing about different cultural groups is important for those doing conservation work. & 4.44 & .75 \\
\hline If I know about a person's culture, I don't need to assess their personal beliefs about conservation * & 4.38 & .73 \\
\hline I am not able to understand perspectives on conservation other than mine. $*$ & 4.32 & .77 \\
\hline Many aspects of culture influence beliefs and practices about conservation. & 4.21 & .73 \\
\hline I enjoy working with people who hold beliefs about conservation different from mine. & 3.94 & .85 \\
\hline I find ways to adapt my conservation practices to my interns' cultural preferences. & 3.32 & .81 \\
\hline
\end{tabular}

* Reverse coded items 


\section{\لMacrothink}

The items in aggregate indicated reasonable internal consistency $(\alpha=0.71)$, such that a mean could be computed with all the items. The measure depicted an understanding of the multiple connotations of the 'environment' and conservation work, and that the diversity of perspectives strengthens the field. Several pairs of items in this scale indicated significant relationships, with the strongest relationships between pairs acknowledging there are different perspectives on conservation and the environment, $(r=.94, p<.001)$, acknowledging different perspectives on conservation and appreciating them $(r=.74, p<.001)$, and acknowledging different perspectives on conservation and recognizing they strengthen the field $(r=.72, p<.001)$.

Although means for both measures of cultural competence were high, staff had significantly more agreement with the conservation-related cultural competence measure $(\mathrm{M}=4.30, \mathrm{SD}$ $=.33)$ than with the racial-ethnic one $(\mathrm{M}=4.07, \mathrm{SD}=.37), t(33)=4.30, p<.001$. This finding validates the open-ended feedback; that is, while staff felt their cultural competence about different racial and ethnic groups had not been impacted, their understanding of the cultures of urban and youth's conservation views had certainly grown. The voluntary descriptions of expanded views on conservation suggested their salience over more cultural issues surrounding race and ethnicity that were found to be minor topics in the open-ended responses, even when culture was defined broadly. The correlation between the two means was moderately high, $r$ $(32)=.67, p<.001$, suggesting that appreciating different racial and ethnic groups or the multiple views on conservation work, were both expressions of cultural competence.

\subsection{Personal and Professional Gains}

Staff was also asked what they believed were the most important professional or personal gains from the LEAF program. Of the 34 respondents, 13 felt they gained a new or a refreshing perspective on the environment by interacting with urban youth. Of this group, two commented that they had gained "more hope for the future of conservation".

About half the respondents claimed they developed a new perspective on their own connection with nature:

I get to see things I see every day through the eyes of people who have never seen them before. For example:.. mountain streams, a forest trail, canoeing/kayaking through a wetland, white-tailed deer foraging in an open field. Working with the LEAF program truly, and in a beautifully straight-forward way, reiterates for me why I have a passion for environmental work.

Another nine felt that they gained important leadership skills working with urban teens over the course of the summer. They perceived their leadership role and service as a role model as important outcomes. Some mentioned acquiring specific skills, like improved negotiation skills or being more conscious of modeling desired social interaction behaviors through their LEAF experience. Many described a personal sense of gratification from their leadership accomplishments.

Nearly half the members of the TNC field staff felt that the most important thing they gained from participating with the LEAF interns was their ability to share knowledge. A similar number mentioned the amount of work they were able to accomplish with the help of the LEAF 
interns. They described the youth contribution to achieving work goals as invaluable and important.

\subsection{General Reactions to Student Interns}

The survey also explored what had surprised staff the most about working with the interns, and the extent to which the LEAF program had added value to their experience. Of the 34 staff respondents, 14 mentioned being surprised about interns' engagement and interest in conservation issues or in some cases, their lack of interest. For example, some staff reported they were "surprised and pleased that this year's group in particular, displayed sincere interest and enthusiasm for the work they were doing." Other staff reported being surprised by "the varying levels of engagement of the LEAF interns." Of the 11 staff members who commented about the surprising experience of working with interns, four mentioned an aspect of the interns' learning process or level of knowledge. Another four commented about the LEAF interns' lack of knowledge, with one startled by the discovery that some of the students "had not heard of climate change. " In general, however, the majority of staff had positive feedback about the interns' attitudes, maturity, and motivation.

\subsection{Changes in Practice after LEAF}

Staff members were asked what they might do differently in their work as a result of participating in the LEAF program. Most staff $(n=27)$ reported changing or intending to change some aspect of their work following their involvement with LEAF. Some staff focused on how they would figure out what projects future LEAF interns could potentially do, based on their experience with the 2012 cohort. Other staff felt inspired by the LEAF student interns to involve local schools and communities more in TNC projects throughout the year, especially to involve them around topics covering natural resources and nature.

Other staff members felt that the LEAF program has changed their perspective on how they approach their work, and led them to think about their projects as offering more meaningful opportunities for youth development than before the internship. Overall, the results suggested that their new perspectives on conservation work would potentially translate into changes in their existing professional work.

\subsection{Cultural Competence for Different Groups}

The survey included a set of questions assessing staff's background, some of which were measured using categorical variables. These included whether or not they had worked with urban youth in the past and where they grew up (urban, suburban, or rural). However, due to the small sample size, the sub-groups within each variable were either very small or disproportionate in size. This variation and size precluded testing for statistical differences in the two competence measures between the groups defined by these categories. The means for these groups are reported, indicating similar means for the two different measures (see Figures 2 and 3). Means are described without asserting differences and should be interpreted with caution, since they do not necessarily represent generalizable findings. 


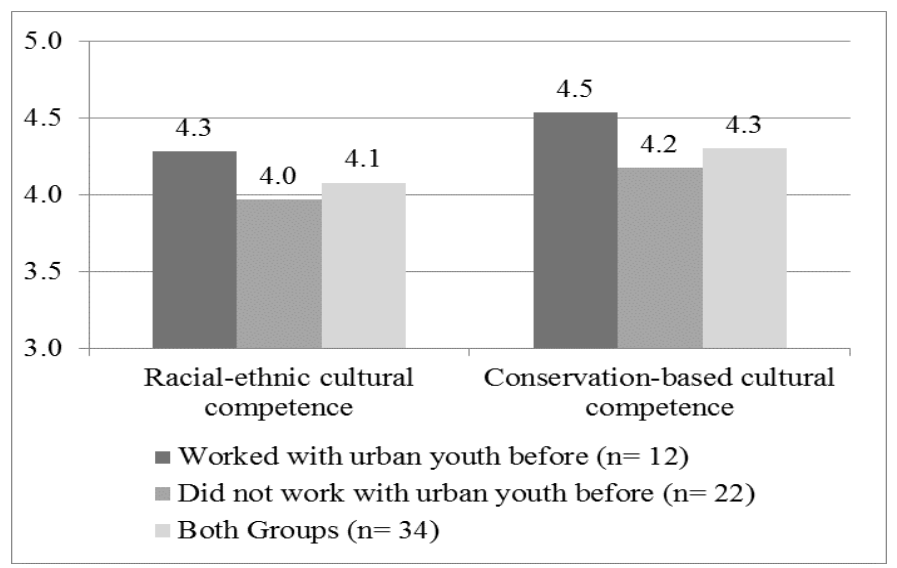

Figure 2. Cultural competence subscales grouped by previous work with urban youth

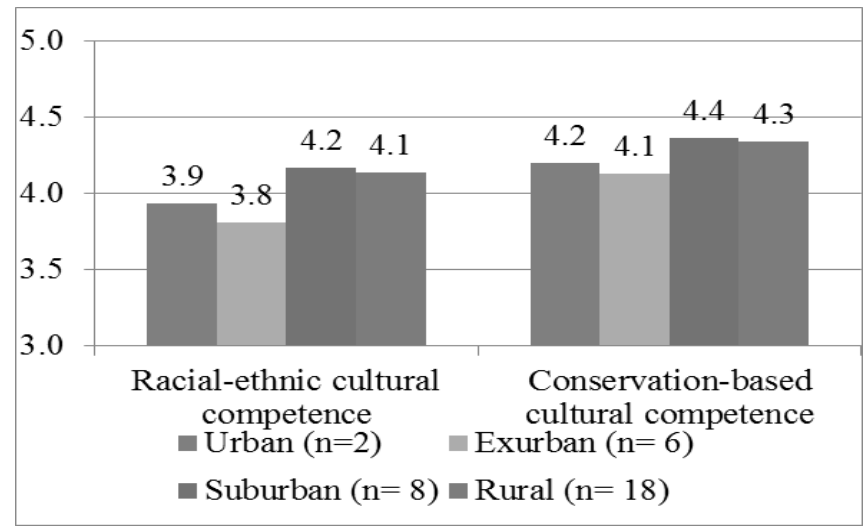

Figure 3. Cultural competence subscales grouped by area in which staff were raised.

Staff who had worked with urban youth previously compared to those who had not appeared to score higher on both aspects of cultural competence (Figure 2). Racial-ethnic cultural competence also appeared higher for those who were raised in rural and suburban areas compared to in urban and exurban locations (Figure 3). We speculate, with a larger and more proportionate sample size between groups, the practical and statistical significance of these potential differences could be surfaced.

\section{Discussion}

Data from the online survey with TNC staff who supported the LEAF summer internship revealed that they developed cultural competence through their interactions with LEAF interns, grew more respectful, advanced their own thinking about conservation work, and found value in learning from their racial and ethnic difference. The qualitative and quantitative data was triangulated to provide evidence that staff had acquired a broader understanding of culture through their experiences with LEAF. Moreover, at the end of the program, they claimed that they were more attuned to the multiple and divergent perspectives on conservation work.

It should be noted that results from the survey items addressing racial and ethnic heritage did not surface any concerns related to differences in racial-ethnic cultural heritage during their close interactions with the interns, suggesting that TNC staff had confidence and skills working 
with people from different cultures prior to their interactions with the LEAF interns.

The qualitative items attempted to assess the extent to which the LEAF experience had specifically contributed to skill development, in terms of their negotiation of different cultures. Though asked indirectly, some of the items asked about the ways in which staff involvement in LEAF had helped them value different cultures, trying to understand the ways in which competence had developed. Others asked about the ways LEAF enabled interaction with people holding different perspectives on conservation and expanded their thinking. While the quantitative survey items may not have been completely immune to social desirability (that is, staff may have responded in ways they thought the researchers wanted to hear), responses to the open-ended prompts validated the responses and clarified that there was no contradictory subtext to these responses and that the results were valid. We concluded that the program positively increased staff skills and cultural competencies.

These data offered evidence of considerable transformation in staff through their close work with LEAF interns. The design of the program appears to be particularly useful in providing staff with new perspectives for how they approach their work and for its relevance to American culture as manifest in urban areas, starkly different from where the staff members were located. Of particular note was the finding about staff's understandings of how urban youth think about conservation and justice issues. Compared to traditional conceptualizations of culture that focus on socio-demographic factors, staff became more aware of the distinct priorities and values held by urban youth and how these groups might perceive TNC's conservation efforts.

Recent urban conservation efforts have seen a focus on practices that integrate civic and ecological priorities (such as, community gardening, planting trees, and oyster-bed restoration), with implications for the urban environment as well as the communities where they occur (Tidball \& Krasny, 2010). This body of research draws attention to the unique characteristics of urban environmental problems and their relation to human wellbeing, where community efforts to address the challenges also foster positive outcomes in the people (skill development, employment, or improved health). The current research found that for TNC staff, LEAF seemed to have provided the opportunity to critically think about these distinct ways of approaching conservation work that were not on their radar before the internship. LEAF interns appear to have helped TNC staff recognize new conservation priorities and re-contextualize and broaden the scope of their work in the process. Going a step beyond mere recognition, staff also appeared to greatly appreciate the value of this learning and considered it an important step toward thinking about how to talk about their conservation goals.

In addition to these positive findings, the results surfaced some negative aspects of staff's experience that are instructive for discourse in EE. Responses suggested that rethinking conservation priorities is an emotionally taxing effort. Specifically, even as they were made aware of and understood the implications of others' perspectives on conservation, some staff provided candid feedback on the internal struggles they were experiencing as a result of the gained insight. These narratives were reminiscent of the implications of unique perspectives on environmental education, that can potentially manifest as communication barriers and intense debate tied to deep-seated motivations perceived to be driving environment-geared work 
(Disinger, 1997). Recent work on the emotional burden experienced by conservationists (Fraser, et al., 2013) further highlights the cognitive struggle of grappling daily with the realities of environmental degradation. This is not surprising given the unique ways educators working around environmental and community issues think about their work, often appearing to be contradictory to one another (Fraser, et al. 2014).

Close encounters with those holding divergent perspectives (as perceived) are likely to intensify negative affective reactions and may help to explain the experience the TNC staff were describing as part of their emotional negotiation. Specifically, confronting other perspectives may have initially been considered a threat to one's values and beliefs, and any defensive reactions may have hampered effective communications between staff and interns. However, the results from the survey indicated that even though some TNC staff may have experienced intense emotions while trying to understand intern perspectives on conservation, they were tied to positive outcomes, in terms of their competence around youth and conservation perspectives. That is, despite recognizing that youth's thinking of conservation was different from theirs, they were able to respect and appreciate them, a promising finding for close interactions between those holding different views on conservation work.

The results suggested that creating additional opportunities for staff to share these thoughts with their peers within the organization would likely increase the learning and retention of these newfound understandings. The self-awareness of these respondents' emotional experiences - their descriptions of hopefulness, and their experience of the transformative nature of new perspective taking - bodes well for the value of LEAF and conservation education. We argue, based on these results that encouraging critical reflection on one's individual perspectives on environmental priorities in relation to others' views is critical to TNC staff's professional development. That TNC staff members working with LEAF interns were mindful of how difficult it is to acknowledge another conservation perspective indicates their openness to personal advancement. Staff's responses suggested that they believed their attempts to more fully understand the perspectives of urban teens will aid in their own ability to remain resilient as the culture shifts around them.

EE in urban areas is manifest as civic practices that integrate a focus on community health and wellness with instrumental goals, such as science learning and skill development (Russ \& Krasny, 2014). Urban areas face distinct environmental challenges that emphasize ways of thinking about the 'environment' across its built and natural features, such that conservation practices may be noticeably different from those farther from cities. As emphasized by recent capacity building efforts funded by the U.S. Environmental Protection Agency to increase networking between those working in $\mathrm{EE}$, youth and community development, and resource management, and related fields (http://www.eecapacity.net/), greater appreciation of different worldviews on the 'environment' is critical. In the context of the evolving field of EE, the current research emphasizes the value of opportunities for educators to reflect on their own and others' understandings of conservation work.

While there is limited attention to such self-reflective practices in EE, structured efforts in teacher education programs using narrative inquiry have found them critical to developing 
cultural awareness and mindful practice for building teachers' professional capacity (West-Olatunji, Behar-Horenstein, \& Rant, 2008). The recently designed professional development tool (Fraser \& Gupta, 2012) may be a promising tool to facilitate critical reflection on one's perspectives on conservation and EE. Beyond surfacing the ongoing debate about EE definitions and perspectives (Disinger, 1997), the results highlighted the importance of critical experiences like LEAF in expanding conservationists' cultural competence in ways that can benefit the field as a whole. The study also highlighted that LEAF, with its intense, collaborative field experience for staff and interns, may similarly encourage greater appreciation of other conservation worldviews in the field and help carry the TNC story more effectively into urban areas throughout the United States.

\subsection{Future Research}

Additional studies need to be conducted to generalize the findings of this study beyond the context of the LEAF program, in other similar informal settings where youth and adult staff have opportunities to work together. The current study with a relatively small group of educators demonstrated distinct ways of thinking about and appreciating culture that were meaningful and valid. However, replication of these results with larger sample sizes will be critical to further establish the validity of these findings. A larger sample size will also enable exploring how staff's experience working with urban youth and their experiences living in urban areas might moderate their development of cultural competence in conservation programs including. Additional studies would also enable validation of the conservation-related cultural competence scale that was developed for this study.

\section{Conclusion}

The study provided valuable insight into the key questions guiding the research. Results using mixed methods indicated that the LEAF internship had added value to staff's cultural competencies in profound ways relating to distinct perspectives on conservation work, beyond typical demographic differences. The unique ways in which their understanding had grown manifested in appreciating the perspectives of youth and worldviews of the environment colored by youth's urban upbringing. Comparatively, their cultural competence related to interactions with other races and ethnicities, had not been as salient or strong.

The fact that the informal experiences, outside of structured professional development, were important for staff who worked closely with urban audiences bodes well for the broader impacts of the program - not only were staff expanding their understanding of the different ways culture is evident in conservation work, their personal and professional growth suggests positive implications for building capacity within the larger field of conservation and EE.

Across decades, numerous scholars have acknowledged diverse voices in EE as an imperative, with little more than lip service in the field to facilitate greater communication between groups with different environmental perspectives. Our research points to the potential of hands-on, applied settings of EE programs to provide valuable cultural lessons. Beyond professional development opportunities that often occur in contexts devoid of intercultural interaction, EE programs involving multicultural groups with focused reflective sessions can be powerful to 
understand and appreciate the various ways EE and conservation may be approached. Though the current research focused on a youth conservation program, we speculate that other EE and conservation education programs focusing on different audience groups will also afford educators, working closely with them, cultural competence opportunities. In order to leverage this learning, we recommend $\mathrm{EE}$ and conservation education programs actively create ways and means to allow educators the scope and space to reflect on and articulate their experiences of interacting with groups holding a different perspective on the environment.

The strength of the research is in surfacing a broader understanding of culture beyond race and ethnicity, to include values guiding environmental work based on age and connection to urbanity. For EE to be responsive and applicable in a growing urban world, the culture embedded in how people think about the environment needs to be made explicit in any EE setting. The strong emotional experience guiding EE work makes it especially critical that the reflection and sharing occur in thoughtfully structured ways. Documenting the exciting possibilities for staff cultural competence in an informal conservation education setting, the current research is intended to call attention to an often overlooked, but fertile ground to build educators' cultural capacity in the journey to strengthen EE.

\section{Acknowledgement}

The research was conducted as part of the evaluation of The Nature Conservancy's Leaders in Environmental Action for the Future program offered in LEAF school partners through The Nature Conservancy's Cost Center \#1981203020, funded in part by the Toyota USA Foundation. The authors serve as independent external evaluators for the project and are solely responsible for the content. The authors thank Brigitte Griswold, Director of Youth Programs for The Nature Conservancy, Rachel Vasquez, LEAF Program Manager, and Desiree Herrera, LEAF Program Coordinator for their support on this study; and the 2012 LEAF Staff who provided their feedback on their experiences working with the interns.

\section{References}

Agyeman, J. (2003). Under-participation and ethnocentrism in environmental education research: Developing culturally sensitive research approaches. Canadian Journal of Environmental Education, 8, 80-94.

Agyeman, J. (2002). Culturing environmental education: From First Nation to frustration. Canadian Journal of Environmental Education, 7, 5-12.

Disinger, J. F. (1997). Environmental education's definitional problem. In H. Hungerford, W. Bluhm, T. Volk, and J. Ramsey (Ed.). Essential Readings in Environmental Education, 17 - 32. Champaign, IL: Stipes Publishing

Doorenbos, S., Schim, S.M., Benkert, R. \& Borse, N.N. (2005). Psychometric evaluation of the cultural assessment instrument among healthcare providers. Nursing Research, 54, 324-331. http://dx.doi.org/10.1097/00006199-200509000-00006

Gupta, R., Fraser, J., \& Krasny, M. E. (in preparation). Building trust and respect as first steps in creating equitable partnerships among environmental and community educators. 


\section{Macrothink}

Environmental Management and Sustainable Development

ISSN 2164-7682

2014, Vol. 3, No. 2

Ford, P. (1986). Outdoor education: Definition and philosophy. ERIC Clearinghouse on Rural Education and Small Schools, Las Cruces, New Mexico. Office of Educational Research and Improvement (ED): Washington, DC. Retrieved 31 October, 2014, from http://files.eric.ed.gov/fulltext/ED267941.pdf

Fraser, J. R., \& Gupta, R. (2012). Perspectives on Environmental Education: Curriculum, Instructor's Guide and Materials, (NewKnowledge Resource \#EPA.6361.03). New York, New Knowledge Organization Ltd.

Fraser, J. R., Gupta, R., \& Krasny, M. E. (2014). Practitioners' perspectives on the purpose of environmental education. Environmental Education Research, http://dx.doi.org/10.1080/13504622.2014.933777

Fraser, J. R., Pantesco, V., Plemons, K., Gupta, R., \& Rank, S. J. (2013). Sustaining the conservationist Ecopsychology, 5, 70-79. http://dx.doi.org/10.1089/eco.2012.0076

Kahn Jr, P. H. (1999). The human relationship with nature: Development and culture. The MIT Press

Kato, K. (2002). Environment and culture: Developing alternative perspectives in environmental discourse. Canadian Journal of Environmental Education 7, 110-116.

Krasny, M. E., Lundholm, C., Shava, S., Lee, E., \& Kobori, H. (2013). Urban Landscapes as Learning Arenas for Biodiversity and Ecosystem Services Management. In Urbanization, Biodiversity and Ecosystem Services: Challenges and Opportunities (pp. 629-664). Springer Netherlands. http://dx.doi.org/10.1007/978-94-007-7088-1_30

Marouli, C. (2002). Multicultural environmental education: Theory and practice. Canadian Journal of Environmental Education, 7, 26-42.

Nordström, H. K. (2008). Environmental education and multicultural education-Too close to be separate?. International Research in Geographical and Environmental Education, 17, 131-145. http://dx.doi.org/10.1080/10382040802148604

Russ, A., \& Krasny, M. E. (2014). In Monroe, M. C., \& Krasny, M. E. (Eds.), Across the spectrum: Resources for environmental educators (2nd edition), Washington, D.C.: NAAEE.

Schulze, S. (2005). Philosophical positions in environmental education. In C. P. Loubser (Ed.) Environmental education: Some South African perspectives (pp. 57- 71). Pretoria: Van Schaik Publishers. http://dx.doi.org/10.2167/irgee232.0

Tallis, H., \& Lubchenco, J. (2014). Working together: A call for inclusive conservation. Nature, 515, 27-8. http://dx.doi.org/10.1038/515027a

Tidball, K.G., \& Krasny. M.E. (2010). Urban environmental education from a social-ecological perspective: conceptual framework for civic ecology education. Cities and the Environment, 3, 1-20. http://escholarship.bc.edu/cate/vol3/iss1/11

Triandis, H. C. (1996). The psychological measurement of cultural syndromes. American Psychologist, 51, 407-415. http://dx.doi.org/10.1037/0003-066X.51.4.407 
West-Olatunji, C., Behar-Horenstein, L., \& Rant, J. (2008). Mediated lesson study, collaborative learning, and cultural competence among early childhood educators. Journal of Research in Childhood Education, 23, 96-108. http://dx.doi.org/10.1080/02568540809594648

\section{Appendix}

Appendix 1. Staff survey

1. Please answer the following questions.

First Name:

Last Name:

TNC Chapter:

2. Please indicate how closely you worked with the 2012 LEAF Program participants. Approximately how long did you work with them?

- All throughout the four week program

- Two weeks

- A week

- Less than a week

- A day

- A few hours

- Less than an hour

- Other (please explain)

3. Please indicate the number of years you have been participating in the LEAF Program.

4. What was the most important thing you gained (personally or professionally) from the 2012 LEAF Program?

6. What surprised you the most working with the students?

7. What do you think you might do differently in your work because of your LEAF experience?

8. For the rest of the questions in this survey, please think about your interaction with the mentors and students during the 2012 LEAF program.

9. My work through LEAF exposed me to cultures other than my own.

- Strongly Disagree

- Disagree 


\section{Macrothink

- Neither Agree nor Disagree

- Agree

- Strongly Agree

10. Briefly describe how LEAF helped expose you to cultures other than your own. If you did not agree with the above sentence, please explain why.

11. My work through LEAF helped me value cultures other than my own.

- Strongly Disagree

- Disagree

- Neither Agree nor Disagree

- Agree

- Strongly Agree

12. Briefly describe how LEAF helped you value cultures other than your own. If you did not agree with the above sentence, please explain why.

13. My work through LEAF helped me interact with people who approach conservation in other ways than I do.

- Strongly Disagree

- Disagree

- Neither Agree nor Disagree

- Agree

- Strongly Agree

14. Briefly describe how LEAF helped you interact with people who approach conservation in other ways than you do. If you did not agree with the above sentence, please explain why.

15. My work through LEAF helped me expand my thinking about conservation.

- Strongly Disagree

- Disagree

- Neither Agree nor Disagree

- Agree

- Strongly Agree

16. Briefly describe how LEAF helped you expand your thinking about conservation. If you did not agree with the above sentence, please explain why.

17. While continuing to think about your work in conservation, and the people with whom 
you interacted during the LEAF program, please rate your agreement with the following items using the agreement scale below.

$\begin{array}{lcccc}\begin{array}{l}\text { Strongly } \\ \text { Disagree }\end{array} & \text { Disagree } & \begin{array}{c}\text { Neither } \\ \text { Agree nor } \\ \text { Disagree }\end{array} & \text { Agree } & \begin{array}{c}\text { Strongly } \\ \text { Agree }\end{array} \\ & & \end{array}$

I welcome feedback from co-workers about how I interact with people from other cultures.

I welcome feedback from my interns about how I relate to people from other cultures.

I find ways to adapt my conservation practices to my interns' cultural preferences.

O

O

O

about other cultural heritages.

I learn from my interns about other cultural heritages.

I document the adaptations I make with my interns from other cultures.

O $\quad 0 \quad 0$

$\bigcirc$

O

O

18. For each statement, please rate your agreement with it using the agreement scale below.

$\begin{array}{llccc}\begin{array}{l}\text { Strongly } \\ \text { Disagree }\end{array} & \text { Disagree } & \begin{array}{c}\text { Neither } \\ \text { Agree nor } \\ \text { Disagree }\end{array} & \text { Agree } & \begin{array}{c}\text { Strongly } \\ \text { Agree }\end{array} \\ & & & \\ & & & \end{array}$

Race is the most important factor in determining a person's culture.

People with a common cultural background think and act alike.

Many aspects of culture influence beliefs and practices about conservation.

Aspects of cultural diversity need to be assessed for each individual, group, and organization. 
If I know about a person's culture, I do not need to assess their personal beliefs about conservation.

Individuals may identify with more than one cultural group.

19. For each statement, please rate your agreement using the scale below.

\begin{tabular}{|c|c|c|c|c|c|}
\hline & $\begin{array}{l}\text { Strongl } \\
\mathrm{y} \\
\text { Disagre } \\
\mathrm{e}\end{array}$ & $\begin{array}{c}\text { Disagre } \\
\mathrm{e}\end{array}$ & $\begin{array}{l}\text { Neither } \\
\text { Agree nor } \\
\text { Disagree }\end{array}$ & Agree & $\begin{array}{l}\text { Strongly } \\
\text { Agree }\end{array}$ \\
\hline $\begin{array}{l}\text { I enjoy working with people from } \\
\text { other cultural backgrounds. }\end{array}$ & 0 & 0 & 0 & 0 & 0 \\
\hline $\begin{array}{l}\text { Knowing about different cultural } \\
\text { groups is important for those doing } \\
\text { conservation work. }\end{array}$ & 0 & 0 & 0 & 0 & 0 \\
\hline $\begin{array}{l}\text { I enjoy working with people who hold } \\
\text { beliefs about conservation different } \\
\text { from mine. }\end{array}$ & 0 & 0 & 0 & 0 & 0 \\
\hline $\begin{array}{l}\text { I understand that others may think } \\
\text { about the word "environment" } \\
\text { differently than me. }\end{array}$ & 0 & 0 & 0 & 0 & 0 \\
\hline $\begin{array}{l}\text { I am aware that people think about } \\
\text { conservation in different ways. }\end{array}$ & 0 & 0 & 0 & 0 & 0 \\
\hline $\begin{array}{l}\text { I can appreciate ways of thinking } \\
\text { about conservation other than mine. }\end{array}$ & 0 & 0 & 0 & 0 & 0 \\
\hline $\begin{array}{l}\text { I am not able to understand } \\
\text { perspectives on conservation other } \\
\text { than mine. }\end{array}$ & 0 & 0 & 0 & 0 & 0 \\
\hline $\begin{array}{l}\text { Different perspectives on conservation } \\
\text { strengthen the field. }\end{array}$ & 0 & 0 & 0 & 0 & 0 \\
\hline
\end{tabular}

20. Please tell us about your experience working with urban youth. Have you worked with urban youth professionally before LEAF?

- Yes

- No

20a. If you answered "Yes" to the earlier question, which of the following best describes your experience working with urban youth? Before LEAF, my work has... 
- Always involved urban youth

- Mostly involved urban youth

- Sometimes involved urban youth

- Rarely involved urban youth

21. Which of the following areas best describes where you spent the most time growing up?

- Urban

- Exurban (non-agricultural country area with large properties)

- Suburban

- Rural

22. Which of the following best describes the area where you went to college?

- Urban

- Exurban

- Suburban

- Rural

- not applicable

23. Please think about the people with whom you spend the longest amount of time and pick one response below.

- I spend most of my time with people from the same cultural background as me.

- I spend most of my time with people from other cultural backgrounds.

- I spend equal amounts of my time with people from the same cultural backgrounds as me and people from other cultural backgrounds.

Thank you for your responses to this survey about your experience with LEAF this summer. Your feedback will be very helpful to understand LEAF's impact on TNC staff like yourself, and ways to improve it.

Thank you for your participation!

\section{Copyright Disclaimer}

Copyright for this article is retained by the author(s), with first publication rights granted to the journal.

This is an open-access article distributed under the terms and conditions of the Creative Commons Attribution license (http://creativecommons.org/licenses/by/3.0/). 